\title{
Evaluation of Nootropic activity of Ethanolic and Aqueous Root Extracts of Adhatoda vasica nees in Rodents
}

\author{
Kola Venu ${ }^{1}$, Prasenjit Mondal ${ }^{2, *}$, Rajesh BRC ${ }^{3}$, Arjun Goje ${ }^{4}$, Gummadevelly Sandeep ${ }^{5}$, Manish Kumar Thimmaraju ${ }^{6}$, Shaik Chanbasha ${ }^{3}$, \\ Bhookya Padmaja ${ }^{2}$ \\ Vaageswari College of Pharmacy, Karimnagar, Telangana, INDIA. \\ ${ }^{2}$ Vaageswari Institute of Pharmaceutical Sciences, Karimnagar, Telangana, INDIA. \\ ${ }^{3}$ V.L. College of Pharmacy, Raichur, Karnataka, INDIA. \\ ${ }^{4}$ Teegala Ram Reddy College of Pharmacy, Meerpet, Hyderabad, Telangana, INDIA. \\ ${ }^{5}$ Pathfinder Institute of Pharmacy Education and Research, Warangal, Telangana, INDIA. \\ ${ }^{6}$ Balaji Institute of Pharmaceutical Science, Narshampet, Telangana, INDIA.
}

\begin{abstract}
Objectives: The Present study was planned to evaluate the nootropic activity of ehanolic extract of Adhatoda vasica nees (EERAV) and aqueous extract of $A$. vasica (AQERAV) in experimentally induced amnesic models in mice and rats. Methods: AERAV and AQERAV were prepared successively with roots of $A$. vasica using soxhlet apparatus. $L_{50}$ studies for these two extracts were carried out in albino mice up to the dose level of $2000 \mathrm{mg} / \mathrm{kg}$ as per guidelines No. 425 of CPCSEA. EERAV and AQERAV were studied for their nootropic effect evaluated in five different experimental models like Active (Rats) and Passive avoidance, Diazepam, Scopolamine, Sodium nitrite induced amnesia and Sodium nitrite induced hypoxia models all in mice. The parameters studied in nootropic activity are Step Down Latency (SDL), Step Down Error (SDE), Time spent in Shock Zone (TSZ), Number of shocks, Transfer Latency (TL) and Time for cessation of respiration. Results: No mortality observed even at the highest dose tested $(2000 \mathrm{mg} /$ $\mathrm{kg}$ ) and did not produce any significant effect on locomotor activity in mice. Experimental studies have shown that EERAV and AQERAV have exhibited
\end{abstract}

a dose dependent nootropic activity. A Significant nootropic activity was recorded with both the extracts in Active and Passive avoidance, Scopolamine, Diazepam and Sodium nitrite induced amnesia models. AQERAV exhibited a significant nootropic effect with medium and high doses only in Active and Passive avoidance models, scopolamine and Diazepam induced amnesia models. Conclusion: The present study suggests that both extracts possessed a significant nootropic activity in mice and rats.

Key words: A. vasica, Nootropic, Alzheimer's disease, Piracetam, Diazepam.

\section{Correspondence}

Dr. Prasenjit Mondal,

Associate Professor, Vaageswari Institute of Pharmaceutical Sciences,

Karimnagar-505481, Telangana, INDIA.

Phone no: +91 8099879341

Email: prasenjitmyname@gmail.com

DOI: 10.5330/ijpi.2019.4.34

\section{INTRODUCTION}

Learning and memory both can be conceived as a psychological process, as well as change in synaptic neural connectivity. ${ }^{1}$ Learning is defined as the ability to alter behaviour on the basis of experience. Impairment in memory, cognition, compaction, problem solving, judgment and learning is a normal consequence of ageing and is seen in most types of mental illness. Several central depressants including alcohol, scopolamine and hallucinogens can impair memory. ${ }^{2}$ Alzheimer's disease is a neurodegenerative disorder that destroys cells in the brain, leading cause of dementia, a condition that involves gradual memory loss, decline in the ability to perform routine tasks, disorientation, difficulty in learning, loss of language skills, impairment of judgment and personality changes. ${ }^{3}$ As the disease progresses, people with Alzheimer's are unable to care for themselves and the loss of brain cells eventually lead to the failure of other systems in the body. ${ }^{4}$ Currently there is no cure and the traditional system is directed at managing the symptoms of AD. However there are avenues for the development of new therapies that will hopefully be directed towards improvements of cognitive functions. A great research is required for early diagnosis of this condition to develop newer and effective drugs to prevent or halt the progression of the disease. Since allopathic system of medicine is yet to provide a radical cure hence it is worthwhile to look for new directions which would minimize the memory loss in elderly patients. ${ }^{5,6}$ At this juncture, to identify a novel cognitive enhancer arises and when it has to be virtually free from severe deleterious effects, one has to turn to nature i.e; from natural source. In recent years, there has been phenomenal rise in the interest of scientific community about herbs to explore the pharmacological actions or to confirm the veracity of claims made for such in the official books of Ayurveda and Siddha. Several plants have been reported to possess nootropic activity. Some nootropic agents (eg: Piracetam) are widely used but the resulting chemophobia associated with them and other similar agents has made their use limited. So it is worthwhile to explore medicines from the traditional system in the treatment of these cognitive disorders. Based on the above concept, several herbal formulations have been widely marketed, claiming to be useful in memory disorders. Adhatoda vasica nees which is well known to have vasicine, vasicinone, vasicol and vasicinolone as a various phytoconstituents from its root and leaf extracts. And considered for its reported antiasthamatic, bronchodialotor, wound healing, insecticidile, antiulcer, antibacterial and anti-allergic activities. ${ }^{7}$ Ayurveda, an ancient Indian system of medicine had reported various plants with the caliber of memory enhancing activity and the plant Adhatoda vasica ${ }^{8}$ is one such recommended as a memory enhancing agent for its nootropic activity, but it has not been reported yet. Therefore the present investigation was aimed at studying the nootropic activity of alcoholic 
and aqueous extracts of roots of Adhatoda vasica in different models of experimental animals like mice and rats.

\section{MATERIALS AND METHODS}

\section{Plant Material}

Adhatoda vasica nees was collected in the month of June from Raichur district, formally identified and authenticated by Dr. B. Hementh Kumar, professor of pharmacognosy, with a authentication no. VLCP/ plantauth-30//2018/0310, From VL college of Pharmacy, Raichur, Karnataka and were dried in shade at room temperature then subjected to size reduction to a fine powder with the help of mixer grinder. The figure of the plant and root of $A$. vasica shown in Figure 1.

\section{Preparation of ethanolic extract:}

The bark powder (750 gm) was packed in a soxhlet apparatus and extracted with one litre ethanol (95\%) for $18 \mathrm{hr}$ at $>78^{\circ} \mathrm{C}$. Appearance of colourless solvent in the siphon tube was taken as the termination of extraction. The extract was then transferred into a previously weighed empty beaker and evaporated to a thick paste on the water bath, maintained at $<50^{\circ} \mathrm{C}$. The ethanolic extract of root of $A$. vasica (EERAV) was appeared dark brown amorphous in nature with percentage yield of $1 \%$.

\section{Preparation of aqueous extract:}

About $100 \mathrm{~g}$ of fruit powder was taken in a round bottom flask $(2000 \mathrm{ml})$ and macerated with $500 \mathrm{ml}$ of distilled water for $24 \mathrm{hr}$ with occasional shaking in a closed vessel. $10 \mathrm{ml}$ of chloroform was added as a preservative .Then the marc was removed by filtering the extract and then concentrated on a water bath maintained at $50^{\circ} \mathrm{C}$. The extract was finally air dried thoroughly to remove all traces of the solvent. The aqueous extract of root of A. vasica (AQERAV) was appeared dark brown sticky in nature with percentage yield of $1 \%$.The two extracts were examined for their colour and consistency. Their percentage yield was calculated with reference to air dried sample used for extraction then stored in an air tight containers in a refrigerator below $-4^{\circ} \mathrm{C}$.

\section{Experimental animals}

Albino rats (Wistar strain) of both sex weighing between 150-200 gm and Albino mice of either sex weighting between 16-25 g were procured from National Centre for Laboratory Animal Sciences, C/O Sri Venkateswara Enterprises, Bengaluru for experimental purpose. After procuring, all the animals were acclimatized for 7 days under standard husbandry condition as, $26 \pm 2^{\circ} \mathrm{C}$ room temperature, with relative humidity 45-55\% and kept light/ dark cycle for 12:12 hr. The animals were fed with synthetic standard diet Amrut Laboratories (Pranava Agro Industries Ltd. Sangli.) Water was allowed ad libitum and strict hygienic conditions were maintained. After obtaining prior permission from Institutional Animal Ethical Committee (IAEC) of V. L. College of Pharmacy Raichur (Karnataka), all animal studies were performed as per rules and regulations in accordance with the guidelines of CPCSEA (Registration Number 557/02/c/CPCSEA $18^{\text {th }}$ February, 2018.).

\section{Chemicals and drugs}

Diazepam [Ranbaxy Laboratories Ltd, Mumbai, India], Piracetam (Micro Labs Ltd, Banglore, India). Phenytoin [Sun Pharmaceutical India. Ltd, Gujarat, India], Scopolamine (Cadila Healthcare Ltd, Goa. India), Sodium nitrite (Merck India Ltd, Mumbai, India) and Ethanol (Nice, Cochin, India) and remaining all the chemicals used were of analytical grade.

\section{Determination of acute oral toxicity $\left(\mathrm{LD}_{50}\right)$}

The acute oral toxicity study of fruit extracts of A. vasica was determined in female albino mice (16-25 g) maintained under standard husbandry conditions. The animals were fasted $4 \mathrm{hr}$ prior to the experiment and Up and Down procedure (OECD Guidelines No. 425) method of CPCSEA was adopted for acute toxicity studies. Animals were administered with single doses of each extract and observed for their mortality during 48 hr study period (short term toxicity). Based on the short term profile of extracts the doses for the next animals were determined. All the animals were observed for long term toxicity ( 7 days). The $\mathrm{LD}_{50}$ studies of the test extracts were conducted up to the maximum dose level of $2000 \mathrm{mg} / \mathrm{kg}$ body wt. $1 / 20^{\text {th }}, 1 / 10^{\text {th }}$ and $1 / 5^{\text {th }}$ doses of the $\mathrm{LD}_{50}$ dose of the individual extracts were selected for the study as low, medium and high doses. ${ }^{9}$

\section{Locomotor activity}

In this method ${ }^{10,11}$ albino mice (18-22 g) of either sex were divided into 8 groups of 6 mice in each was fasted $4 \mathrm{hr}$ prior to the test but water was supplied ad libitum. Group I is normal control which received distilled water 10ml/kg, p.o, Group II receives Piracetam (200 mg/kg, p.o.), Group III, IV and V receives 100, 200 and $400 \mathrm{mg} / \mathrm{kg}$ EERAV whereas VI, VII and VIII receives low dose, $100 \mathrm{mg} / \mathrm{kg}$, p.o100, 200 and $400 \mathrm{mg} /$ $\mathrm{kg}$ AERAV. $1 \mathrm{hr}$ the above treatment, each mouse was placed individually in Photoactometer (INCO, Ambala, India) for a period of $10 \mathrm{~min}$ and locomotor activity was measured in terms of scores.

\section{Determination of Nootropic activity}

\section{Exteroceptive Behavior Models}

Active avoidance paradigm (Shuttle box): In this method, ${ }^{12}$ group I was maintained as normal control, which was given with distilled water only daily once for 14 days. Group II with Piracetam (200 mg/kg, p.o.), which served as standard. Groups III, IV, V and Groups VI, VII and VIII were treated with different doses of EERAV (100, 200 and $400 \mathrm{mg} / \mathrm{kg}$ p.o.) and AQERAV (100, 200 and $400 \mathrm{mg} / \mathrm{kg}$ p.o.) Respectively for 14 days. All groups of rats were trained up to $100 \%$ learning criterion of active avoidance response. During the training period, each rat was placed in one of the two chambers of the Sidman box and after $5 \mathrm{sec}$ the buzzer (conditioned stimulus, CS) was sounded for $2 \mathrm{sec}$ followed by an electric shock (unconditioned stimulus, UCS; $30 \mathrm{v}, 0.5 \mathrm{sec}$ ) through the grid floor. Thereafter, a rest pause of $180 \mathrm{sec}$ was allowed. If the rat jumped within the CS duration to the unelectrified safe box, so as to avoid the USC, it was allowed to rest there for next $30 \mathrm{sec}$. However, if the rat did not show the avoidance response, it was removed from the shock chamber after $180 \mathrm{sec}$ and was initiated for the next trial. The rats were given 10 trials daily until they reached the $100 \%$ criterion of active avoidance response. After an interval of 15 days the rats were subjected to a repeat the test with treatment of different doses of the EERAV and AQERAV in order to assess the retention the previously learned active avoidance response. Similarly nootropic activity of standard drug was evaluated.

Passive avoidance paradigm: In this method ${ }^{13}$ Groups of adult male albino rats 100-150 g each consisting of 6 animals were divided in to the following groups and animals are fasted overnight prior to the test but water was supplied ad libitum. Group I: Normal control (distilled water $10 \mathrm{ml} / \mathrm{kg}$, p.o.), Group II: Piracetam (200 mg/kg, p.o.), Groups III, IV, V and Groups VI, VII and VIII were treated with different doses of AERAV (100, 200 and $400 \mathrm{mg} / \mathrm{kg}$ p.o.) and AQERAV (100, 200 and 400 $\mathrm{mg} / \mathrm{kg}$ p.o.) Respectively for 14 days. The memory- impairing dose of Phenytoin $25 \mathrm{mg} / \mathrm{kg}$ was administered daily for 14 days and the selected doses of EERAV and AQERAV for 7 days i.e. on $8^{\text {th }}$ to $14^{\text {th }}$ day and the parameters mentioned above were noted. All groups of rats were trained up to $100 \%$ learning criterion of active avoidance response. During the 
training period, each rat was placed in one of the two chambers of the Sidman box and after $5 \mathrm{sec}$ the buzzer (conditioned stimulus, CS) was sounded for $2 \mathrm{sec}$ followed by an electric shock (unconditioned stimulus, UCS; 30v, $0.5 \mathrm{sec}$ ) through the grid floor. Thereafter, a rest pause of $180 \mathrm{sec}$ was allowed. If the rat jumped within the CS duration to the unelectrified safe box, so as to avoid the USC, it was allowed to rest there for next $30 \mathrm{sec}$. However, if the rat did not show the avoidance response, it was removed from the shock chamber after $180 \mathrm{sec}$ and was initiated for the next trial. The rats were given 10 trials daily until they reached the $100 \%$ criterion of active avoidance response. After an interval of 15 days the rats were subjected to a repeat the test with treatment of different doses of the EERAV and AQERAV in order to assess the retention of the previously learned active avoidance response. Similarly nootropic activity of standard drug was evaluated.

\section{Interoceptive Behavior Models}

Scopolamine-induced amnesia: In this present method ${ }^{14}$ group of adult Swiss male albino mice $18-25 \mathrm{~g}$, each consisting of 6 animals was divided into following groups and animals are fasted overnight prior to the test but water was supplied ad libitum. Group I was maintained as normal control which was given with distilled water $(10 \mathrm{ml} / \mathrm{kg}$, p.o.), Group II with Scopolamine alone $\left(1 \mathrm{mg} / \mathrm{kg}\right.$, i.p) only on $14^{\text {th }}$ day, Group III with Piracetam (200 mg/kg, p.o.) which served as standard, Groups IV, V, VI, VII, VIII, IX were treated with different doses of EERAV (100,200 and $400 \mathrm{mg} / \mathrm{kg}$ p.o.) and AQERAV (100,200 and $400 \mathrm{mg} / \mathrm{kg}$ p.o.) And after 90 min of the last dose for all the groups III, IV, V, VI, VII, VIII, IX were given with Scopolamine ( $1 \mathrm{mg} / \mathrm{kg}$, i.p.). All groups were treated accordingly as mentioned above for a period of 14 days and Scopolamine was given $1 \mathrm{mg} / \mathrm{kg}$, i.p. $90 \mathrm{~min}$ after last dose of standard and different doses of EERAV and AQERAV to induce impairment of memory through muscuranic system. Transfer latency (TL) was recorded using Elevated Plus maze (EPM) $45 \mathrm{~min}$ and $24 \mathrm{hrs}$ after injection of scopolamine. The apparatus used in this model consists of two open arms $(16 \mathrm{~cm} \times 5 \mathrm{~cm})$ and two closed arms $(16 \mathrm{~cm} \times 5 \mathrm{~cm} \times 12 \mathrm{~cm})$, extended from a central platform $(5 \mathrm{~cm} \times 5 \mathrm{~cm})$ and the maze is elevated to a height of $25 \mathrm{~cm}$ from the floor. Group I was maintained as normal control which was given with distilled water $(10 \mathrm{ml} / \mathrm{kg}$, p.o.) only daily once for 14 days. Group II with Scopolamine $(1.0 \mathrm{mg} / \mathrm{kg}$, i.p. $)$ alone. Group III with Piracetam (200 mg/kg, p.o.) Which served as standard, Groups IV, V, VI, VII, VIII, IX were treated with different doses of EERAV (100,200 and $400 \mathrm{mg}$ / kg p.o.) and AQERAV (100,200 and $400 \mathrm{mg} / \mathrm{kg}$ p.o.) Respectively daily once for 14 days. On the $15^{\text {th }}$ day, 90 min after above treatment, each mouse was placed at the end of an open arm of EPM facing away from the central platform. TL (Transfer latency) was recorded i.e. the time taken by mouse to move into one of the enclosed arms with all its four legs. If the animal did not enter into one of the enclosed arms within 90 $\mathrm{s}$, it was gently pushed into one of the two enclosed arms and the TL was assigned as $90 \mathrm{~s}$. The mouse was allowed to explore the maze for next 10 $\mathrm{s}$ and then returned to its home cage. Retention of this learned-task was examined $24 \mathrm{~h}$ after the $15^{\text {th }}$ day trial. The inflexion ratio was calculated by the formula as follows. ${ }^{70}$

Inflexion ratio $(\mathrm{IR})=\left(L_{0-} L_{\mathrm{t}}\right) / L_{0}$, where $L_{0}$ is the initial TL $(\mathrm{s})$ on $15^{\text {th }}$ day and $L_{\mathrm{t}}$ is the TL (s) on the $16^{\text {th }}$ day.

Diazepam-induced amnesia: In this method ${ }^{15}$ adult Swiss male albino mice $18-25 \mathrm{~g}$, each consisting of 6 animals was divided into the following groups and animals are fasted overnight prior to the test but water was supplied ad libitum. Group I was maintained as normal control which was given with distilled water (10 ml/kg, p.o.), Group II with Diazepam alone $\left(1 \mathrm{mg} / \mathrm{kg}\right.$, i.p) only on $14^{\text {th }}$ day, Group III with piracetam (200 mg/kg, p.o.) which served as standard and Groups IV, V, VI, VII, VIII, IX were treated with different doses of EERAV (100,200 and 400 mg/kg p.o.) and AQERAV (100,200 and $400 \mathrm{mg} / \mathrm{kg}$ p.o.) And after 90 min of the last dose for all the groups III, IV, V, VI, VII, VIII, IX were given with Diazepam (1 mg/kg, i.p).

All groups were treated respectively as mentioned above for a period of 14 days and Diazepam $1 \mathrm{mg} / \mathrm{kg}$ was given i.p $90 \mathrm{~min}$ after the last dose of standard/ EERAV and AQERAV to induce impairment of memory that act through GABAergic system. Transfer latency (TL) was recorded with Elevated Plus Maze (EPM) at $45 \mathrm{~min}$ and $24 \mathrm{hr}$ after injection of Diazepam. The inflexion ratio was calculated by the following formula,

$\mathrm{IR}=\left(\mathrm{L}_{0}-\mathrm{L}_{\mathrm{t}}\right) / \mathrm{L} 0$

Where

$\mathrm{L}_{0}$ - intial transfer latency on the $15^{\text {th }}$ day

$\mathrm{L}_{\mathrm{t}}$ - Transfer latency on $16^{\text {th }}$ day.

Sodium nitrite-induced amnesia: The present method ${ }^{16}$ group of adult Swiss male albino mice 18-25g, each consisting of 6 animals were divided into following groups and animals are fasted overnight prior to the test but water was supplied ad libitum. Group I was maintained as normal control which was given with distilled water $(10 \mathrm{ml} / \mathrm{kg}$, p.o.), Group II with Sodium nitrite alone $(25 \mathrm{mg} / \mathrm{kg} \mathrm{s.c})$ daily once for 14 days Group III with Piracetam (200 mg/kg, p.o.) which served as standard, Groups IV, V, VI, VII, VIII, IX were treated with different doses of EERAV (100,200 and $400 \mathrm{mg} / \mathrm{kg}$ p.o.) and AQERAV (100,200 and $400 \mathrm{mg} / \mathrm{kg}$ p.o.) Respectively daily once for 14 days. All groups were treated according to protocol for a period of 14 days and sodium nitrite $25 \mathrm{mg} / \mathrm{kg}$ was given s.c. route $90 \mathrm{~min}$ after the last dose. There after using Elevated Plus maze (EPM) Transfer latency (TL) will be recorded at $45 \mathrm{~min}$ and $24 \mathrm{hrs}$ after administration of Sodium nitrite. The inflexion ratio was calculated as described earlier.

\section{Statistical analysis}

The results are expressed as the mean \pm SEM. The results obtained from the present study were analyzed using one-way ANOVA followed by Dunnett's multiple comparison tests. Data was computed for statistical analysis by using Graph Pad INSTAT and PRISM Software.

\section{RESULTS}

\section{Determination of acute toxicity $\left(\mathrm{LD}_{50}\right)$}

The mice treated with $2000 \mathrm{mg} / \mathrm{kg}$, p.o dose of AERAV (Alcoholic extract of roots of A. vasica) and AQERAV (Aqueous extract of roots of $A$. vasica) exhibited normal behavior, without any signs of passivity, stereotypy and vocalization. The motor activity and secretory signs were also normal and no sign of depression. Further EERAV and AQERAV 2000 $\mathrm{mg} / \mathrm{kg}$ body weight did not produce any mortality. So $1 / 20^{\text {th }}, 1 / 10^{\text {th }}$ and $1 / 5^{\text {th }}$ doses of $2000 \mathrm{mg} / \mathrm{kg}$ were selected as low, medium and high doses and were tested in the present study to explore nootropic activity.

\section{Locomotor activity}

The effect of AERAV (100, 200 and 400mg) and AQERAV (100, 200 and $400 \mathrm{mg}$ ) on locomotor activity was tested using Actophotometer. This activity was performed to confirm the sedative effect of both EERAV and AQERAV. Both the extracts and Piracetam failed to produce any significant reduction in locomotor activity as compared to normal control. The results are tabulated in the Table 1 and Figure 2.

\section{Effect of EERAV and AQERAV on active avoidance}

\section{learning and retention in rats}

Effect of EERAV and AQERAV on learning and retention was studied using Active avoidance paradigm (Shuttle box) apparatus. In learning period i.e. on the $1^{\text {st }}$ day of the study the number of shocks received and time spent in the shock zone with the standard drug (piracetam) treat- 


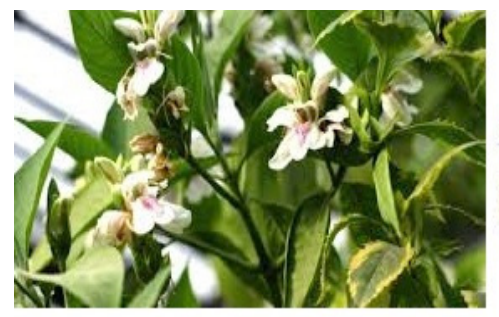

A. vasica Plant

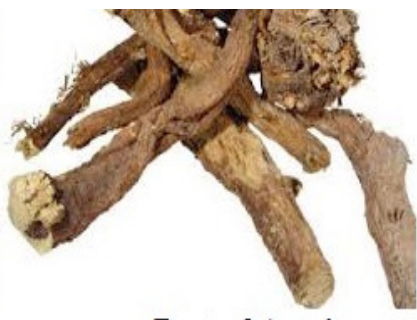

Roots of $A$. vasica
Figure 1: Image of Adathoda vasica, plant and its bark.

\section{Effect of EERAV \& AQERAV on \\ Active avoidance paradigm model (shuttlebox) in rats.}

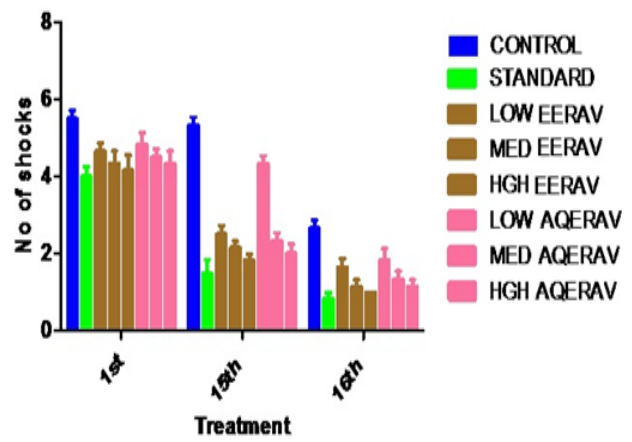

Figure 2: Effect of ethanolic and aqueous extracts on locomotor activity in mice (Actophotometer).

Table 1: Effect of EERAV and AQERAV on locomotor activity in mice (Mean \pm SEM).

\begin{tabular}{ccc}
\hline Treatment & Dose/kg & $\begin{array}{c}\text { Locomotion Scores } \\
(\text { Mean } \pm \text { SEM) }\end{array}$ \\
\hline Control(vehicle) & $10 \mathrm{ml}$ p.o. & $291.5 \pm 17.83^{\text {ns }}$ \\
Piracetam & $200 \mathrm{mg}$ p.o. & $260.5 \pm 16.04^{\mathrm{ns}}$ \\
EERAV & $100 \mathrm{mg}$ p.o. & $229.1 \pm 25.88^{\text {ns }}$ \\
EERAV & $200 \mathrm{mg}$ p.o. & $271.8 \pm 10.87^{\text {ns }}$ \\
EERAV & $400 \mathrm{mg}$ p.o. & $284.8 \pm 18.77^{\mathrm{ns}}$ \\
AQERAV & $100 \mathrm{mg}$ p.o & $222.1 \pm 17.84^{\mathrm{ns}}$ \\
AQERAV & $200 \mathrm{mg}$ p.o & $270.5 \pm 17.78^{\mathrm{ns}}$ \\
AQERAV & $400 \mathrm{mg}$ p.o & $281.3 \pm 23.30^{\text {ns }}$ \\
\hline
\end{tabular}

$n=6$, Significant at $P<0.05^{*}, 0.01^{* *}$ and $0.001^{* * *}$, ns $=$ not significant EERAVEthanolic extract of roots of A. vasica AQERAV- Aqueous extract of roots of A. vasica.

ed group animals was $4.00 \pm 0.25 \mathrm{sec}$ and $15.83 \pm 1.53 \mathrm{sec}$ respectively. When compared with the control group on the $15^{\text {th }}$ and $16^{\text {th }}$ days of the study there was a significant decrease in the above parameters i.e. the number of shocks received was $1.50 \pm 0.34$ and $0.83 \pm 0.16$ respectively and time spent in the shock zone was $8.66 \pm 0.61 \mathrm{sec}$ and $5.50 \pm 0.61 \mathrm{sec}$ respectively. When compared to control group EERAV and AQERAV (low, medium and high doses) treated groups have shown significant nootropic activity in relearning and retention phases of the activity i.e. the number of shocks received and time spent in the shock zone was significantly decreased on the $15^{\text {th }}$ and $16^{\text {th }}$ days of experimental study. The results are tabulated in the Tables 2 and Figure 3.

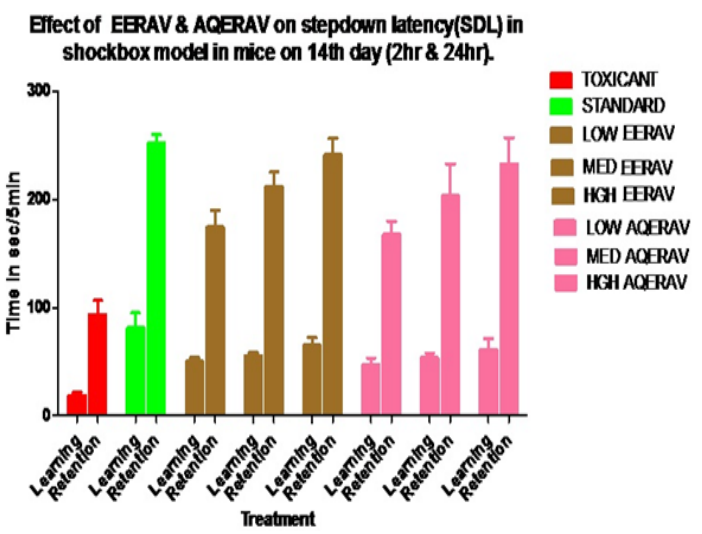

Figure 3: Effect of ethanolic and aqueous extracts on active avoidance paradigm model in rats (Shuttle box).

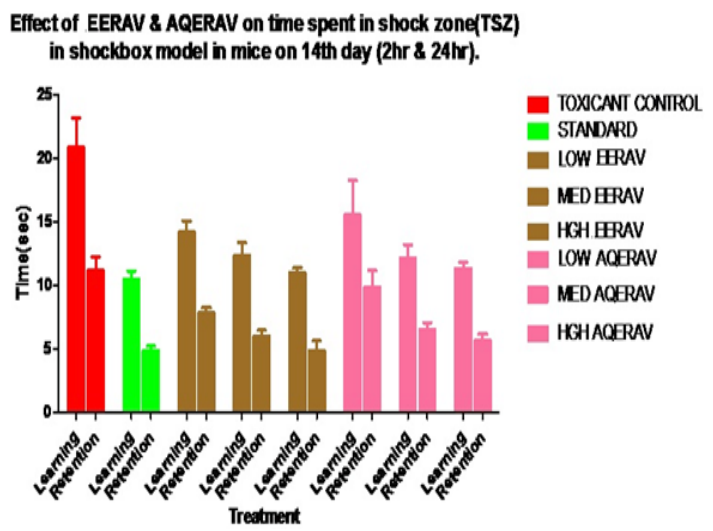

Figure 4: Effect of ethanolic and aqueous extracts on step down latency in shock box model in mice on $14^{\text {th }}$ day. ( $2 \mathrm{hr}$ and $24 \mathrm{hr}$ ).

\section{Effect of EERAV and AQERAV on passive avoidance learning and retention in mice}

Effect of EERAV and AQERAV on learning and retention was tested using passive avoidance paradigm apparatus. When compared to normal control group Phenytoin intoxicated animals have noted with decreased SDL and increased SDE and TSZ. Piracetam treated group has shown significant increase in the SDL and significant decrease in the SDE and TSZ. On $14^{\text {th }}$ day EERAV and AQERAV treated groups have shown dose dependant nootropic action at $2 \mathrm{~h}$ and $24 \mathrm{hr}$ after the last dose of extract. Piracetam, EERAV and AQERAV low, medium and high dose treated groups have shown significant nootropic activity at both $2^{\text {nd }}$ and $24^{\text {th }} \mathrm{h}$ after the last dose of extract and Piracetam on $14^{\text {th }}$ day. But the AQERAV low dose treated group has shown significant effect only with SDL but not with SDE and TSZ at $2^{\text {nd }}$ and $24^{\text {th }} \mathrm{h}$ after the last dose of extract on $14^{\text {th }}$ day. The results are tabulated in the Table 3 and Figure 4.

\section{Effect of EERAV and AQERAV on inflexion ratio in mice (scopolamine-induced amnesic model)}

Scopolamine treated group exhibited with impairment of memory and has shown decrease in IR as compared to normal control group which indicates the induction of amnesia. When compared to IR of normal control group $0.449 \pm 0.032$, scopolamine treated group was noted with impairment of memory as depicted by decrease in IR $0.222 \pm 0.024$. Piracetam, EERAV with Low medium and high dose treated groups have shown significant increase in the IR as recorded by $0.711 \pm 0.032$ and $0.366 \pm 0.035,0.576 \pm 0.030$ and $0.637 \pm 0.026$ respectively. Piracetam, AQERAV with medium and high dose treated groups have shown signif- 
Table 2: Effect of EERAV and AQERAV on Active Avoidance learning and retention in mice (Mean \pm SEM) (shuttle box).

\begin{tabular}{|c|c|c|c|c|c|c|c|}
\hline \multirow[t]{3}{*}{ Treatment } & \multirow[t]{3}{*}{ Dose/ kg } & \multicolumn{3}{|c|}{ Number Of Shocks In 10 Trails } & \multicolumn{3}{|c|}{ Time Spent In Shock Zone For 10 Trails (sec) } \\
\hline & & $\begin{array}{c}\text { Learning } \\
\text { (acquisition) }\end{array}$ & Relearning & Retention & $\begin{array}{c}\text { Learning } \\
\text { (acquisition) }\end{array}$ & Relearning & Retention \\
\hline & & $1^{\text {st }}$ day & $15^{\text {th }}$ day & $16^{\text {th }}$ day & $1^{\text {st }}$ day & $15^{\text {th }}$ day & $16^{\text {th }}$ day \\
\hline Control(vehicle) & $10 \mathrm{ml}$ p.o. & $5.50 \pm 0.22$ & $5.33 \pm 0.21$ & $2.66 \pm 0.21$ & $26.66 \pm 1.45$ & $23.16 \pm 1.53$ & $16.33 \pm 1.17$ \\
\hline Piracetam & $200 \mathrm{mg}$ p.o. & $4.00 \pm 0.25$ & $1.50 \pm 0.34 * *$ & $0.83 \pm 0.16 * *$ & $15.83 \pm 1.53$ & $8.66 \pm 0.61 * *$ & $3.66 \pm 0.33 * *$ \\
\hline EERAV & $100 \mathrm{mg}$ p.o. & $4.66 \pm 0.21$ & $2.50 \pm 0.22 * *$ & $1.66 \pm 0.21 * *$ & $19.83 \pm 2.10$ & $15.83 \pm 1.66 *$ & $10.83 \pm 3.06 *$ \\
\hline EERAV & $200 \mathrm{mg}$ p.o. & $4.33 \pm 0.33$ & $2.16 \pm 0.16 * *$ & $1.16 \pm 0.16 * *$ & $16.33 \pm 1.20$ & $9.00 \pm 1.03 * *$ & $5.83 \pm 0.70 * *$ \\
\hline EERAV & 400mg p.o. & $4.16 \pm 0.40$ & $1.83 \pm 0.16 * *$ & $1.00 \pm 0.00 * *$ & $14.16 \pm 1.53$ & $7.50 \pm 0.67 * *$ & $4.16 \pm 0.30 * *$ \\
\hline AQERAV & 100mg p.o & $4.83 \pm 0.30$ & $4.33 \pm 0.21 *$ & $1.83 \pm 0.30 *$ & $20.00 \pm 1.18$ & $20.66 \pm 2.57^{\mathrm{ns}}$ & $14.33 \pm 0.55^{\mathrm{ns}}$ \\
\hline AQERAV & 200mg p.o & $4.50 \pm 0.22$ & $2.33 \pm 0.21 * *$ & $1.33 \pm 0.21 * *$ & $17.66 \pm 1.05$ & $11.00 \pm 2.11 * *$ & $6.16 \pm 0.47 * *$ \\
\hline AQERAV & 400mg p.o & $4.33 \pm 0.33$ & $2.00 \pm 0.25 * *$ & $1.16 \pm 0.16 * *$ & $14.33 \pm 1.66$ & $7.33 \pm 1.68 * *$ & $5.50 \pm 0.56 * *$ \\
\hline
\end{tabular}

$n=6$, Significant at $P<0.05^{\star}, 0.01^{* *}$ and $0.001^{\star * *}$, ns $=$ not significant EERAV- Ethanolic extract of roots of $A$. vasica AQERAV- Aqueous extract of roots of $A$. vasica

Table 3: Effect of EERAV and AQERAV on passive avoidance learning and retention (Shock box model) in mice (Mean \pm SEM).

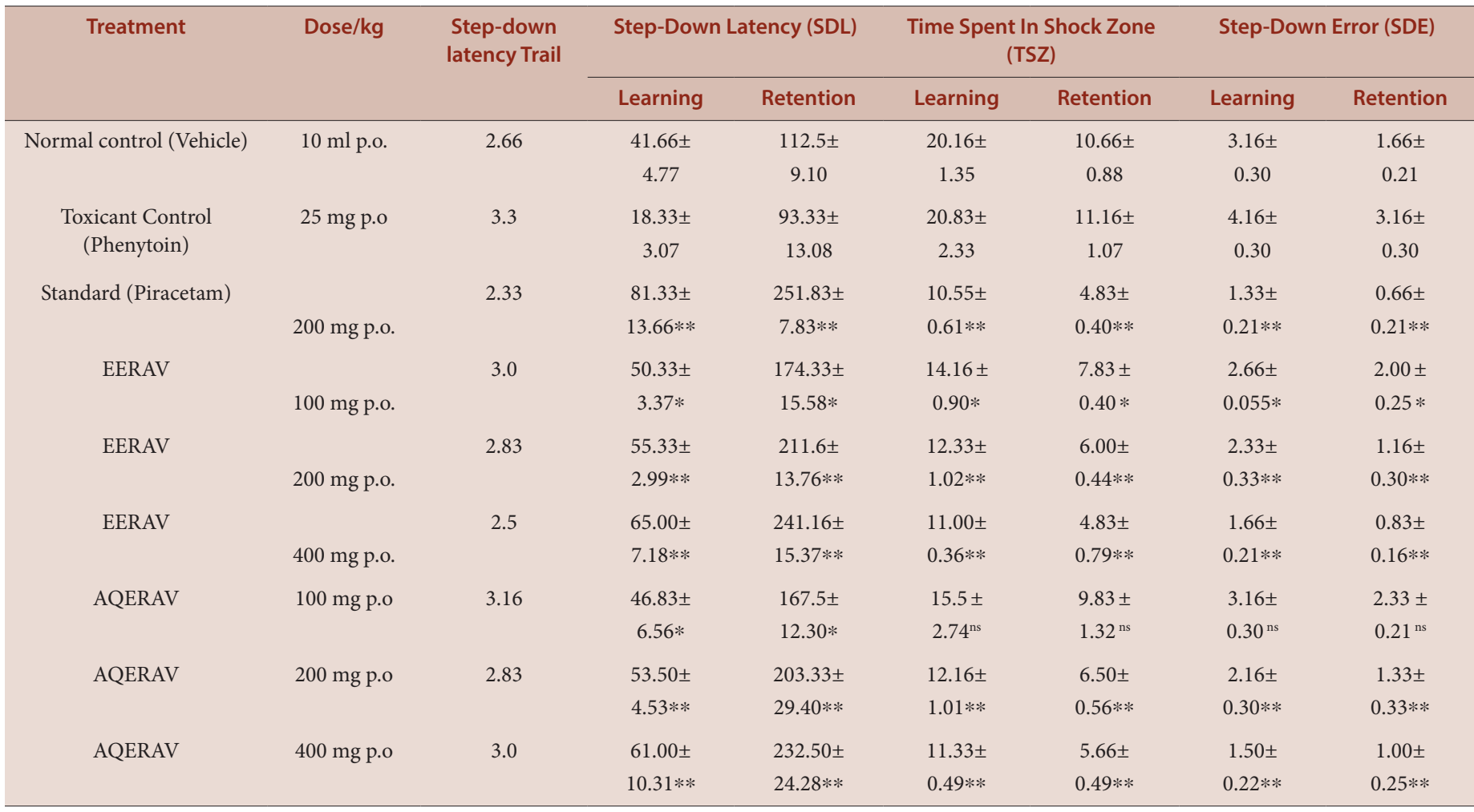

$n=6$, Significant at $P<0.05^{\star}, 0.01^{* *}$ and $0.001^{* * *}$, ns $=$ not significant. EERAV- Ethanolic extract of roots of $A$. vasica AQERAV- Aqueous extract of roots of $A$. vasica

icant increase in the IR as recorded by $0.711 \pm 0.032,0.554 \pm 0.020$ and $0.604 \pm 0.009$ respectively. Whereas the AQERAV lower doses treated group showed insignificant effect with IR $0.347 \pm 0.011$. The results are tabulated in the Table 4.

\section{Effect of EERAV and AQERAV on inflexion ratio in mice (Diazepam-induced amnesic model)}

When compared to normal control IR $0.474 \pm 0.016$, Diazepam has induced dose dependent amnesia and in this amnesic model. When compare to toxicant group a decrease in IR $0.287 \pm 0.034$ was observed. Piracetam has shown a significant increase in the IR $0.664 \pm 0.009$ EERAV with Low, medium and high dose treated groups have shown significant increase in the IR $0.390 \pm 0.024,0.580 \pm 0.014,0.651 \pm 0.025$ respectively and AQERAV with medium and high dose treated groups have shown significant increase in the IR $0.567 \pm 0.014,0.639 \pm 0.010$ respectively whereas the AQERAV lower dose treated group showed an insignificant effect on as noted by IR $0.418 \pm 0.013$. The results are tabulated in the Table 5 .

\section{Effect of EERAV and AQERAV on inflexion ratio in mice (Sodium nitrite-induced amnesic model)}

Sodium nitrite (induces impairment of memory), treated group has shown decrease in IR $0.159 \pm 0.011$ as compared to normal control group IR $0.410 \pm 0.016$, which indicates the induction of amnesia. Piracetam 
Table 4: Effect of AERAV and AQERAV on inflexion ratio in Scopolamine induced amnesic model in mice (Mean \pm SEM).

\begin{tabular}{ccc}
\hline Treatment & Dose/kg & $\begin{array}{c}\text { Inflexion ratio } \\
\text { (mean } \pm \text { SEM) }\end{array}$ \\
\hline Normal control (vehicle)S & $10 \mathrm{ml}$ p.o. & $0.449 \pm 0.032$ \\
Scopolamine alone & $1.0 \mathrm{mg}$ i.p. & $0.222 \pm 0.024$ \\
Piracetam + Scopolamine & $200 \mathrm{mg}$ p.o. $+1.0 \mathrm{mg}$ i.p. & $0.711 \pm 0.032^{\star *}$ \\
AERAV + Scopolamine & $100 \mathrm{mg}$ p.o. $+1.0 \mathrm{mg}$ i.p. & $0.366 \pm 0.035^{*}$ \\
AERAV + Scopolamine & $200 \mathrm{mg}$ p.o. $+1.0 \mathrm{mg}$ i.p. & $0.576 \pm 0.030^{* *}$ \\
AERAV + Scopolamine & $400 \mathrm{mg}$ p.o. $+1.0 \mathrm{mg}$ i.p. & $0.637 \pm 0.026^{* *}$ \\
AQERAV + Scopolamine & $100 \mathrm{mg}$ p.o. $+1.0 \mathrm{mg}$ i.p. & $0.347 \pm 0.011^{\mathrm{ns}}$ \\
AQERAV + Scopolamine & $200 \mathrm{mg}$ p.o. $+1.0 \mathrm{mg}$ i.p. & $0.554 \pm 0.020^{*}$ \\
AQERAV + Scopolamine & $400 \mathrm{mg}$ p.o. $+1.0 \mathrm{mg}$ i.p. & $0.604 \pm 0.009^{* *}$ \\
\hline
\end{tabular}

$n=6$, Significant at $P<0.05^{\star}, 0.01^{* *}$ and $0.001^{* * *}$, ns = not significant EERAVEthanolic extract of roots of A. vasica AQERAV- Aqueous extract of roots of A. vasica

Table 5: Effect of AERAV and AQERAV on inflexion ratio in Diazepam induced amnesic model in mice (Mean \pm SEM).

\begin{tabular}{ccc}
\hline Treatment & Dose/ kg & $\begin{array}{c}\text { Inflexion Ratio } \\
\text { (mean } \pm \text { SEM) }\end{array}$ \\
\hline $\begin{array}{c}\text { Normal } \\
\text { control(vehicle) }\end{array}$ & $10 \mathrm{ml}$ p.o. & $0.474 \pm 0.016$ \\
Diazepam alone & mg i.p. & $0.287 \pm 0.034$ \\
Piracetam + Diazepam & $200 \mathrm{mg}$ p.o. $+1.0 \mathrm{mg}$ i.p & $0.664 \pm 0.009^{* *}$ \\
AERAV + Diazepam & $100 \mathrm{mg}$ p.o. $+1.0 \mathrm{mg}$ i.p. & $0.390 \pm 0.024^{*}$ \\
AERAV + Diazepam & $200 \mathrm{mg}$ p.o. $+1.0 \mathrm{mg}$ i.p. & $0.580 \pm 0.014^{* *}$ \\
AERAV + Diazepam & $400 \mathrm{mg}$ p.o. $+1.0 \mathrm{mg}$ i.p. & $0.651 \pm 0.025^{* *}$ \\
AQERAV + Diazepam & $100 \mathrm{mg}$ p.o. + 1.0 mg i.p. & $0.418 \pm 0.013^{\text {ns }}$ \\
AQERAV + Diazepam & $200 \mathrm{mg}$ p.o. $+1.0 \mathrm{mg}$ i.p. & $0.567 \pm 0.014^{*}$ \\
AQERAV + Diazepam & $400 \mathrm{mg}$ p.o. $+1.0 \mathrm{mg}$ i.p. & $0.639 \pm 0.010^{* *}$ \\
\hline
\end{tabular}

$n=6$, Significant at $P<0.05^{\star}, 0.01^{\star *}$ and $0.001^{\star * *}$, ns $=$ not significant AERAVAlcoholic extract of roots of $A$. vasica AQERAV- Aqueous extract of roots of A. vasica

has shown a significant increase in the IR $0.695 \pm 0.033$ when compare to toxicant group. EERAV with Low, medium and high dose treated groups have shown significant increase in the IR $0.317 \pm 0.009,0.534 \pm 0.021$, $0.605 \pm 0.031$ respectively and AQERAV with Low, medium and high dose treated groups have shown significant increase in the IR $0.314 \pm$ $0.011,0.509 \pm 0.024,0.569 \pm 0.029$ respectively. The results were tabulated in the Table 6 .

\section{DISCUSSION}

Nootropic agents represent a new class of psychotropic agents with selective facilitatory effect on integrative functions of the central nervous system, particularly on intellectual performance, learning capacity and memory. ${ }^{17}$ In the present study, we have focused upon exploring the potential of an Indian medicinal plant, "A. vasica" for its efficacy in reversing the memory deficits and for its improving acquisition and memory retention in experimental animals. The mice treated with EERAV and AQERAV, $2000 \mathrm{mg} / \mathrm{kg}$, p.o. exhibited normal behavior and did not produce any mortality. Locomotor activity is considered as an index of alertness and a decrease in it would indicate sedative activity. EERAV and AQERAV with $100 \mathrm{mg}, 200 \mathrm{mg}$ and $400 \mathrm{mg} / \mathrm{kg}$, dose treatment was
Table 6: Effect of AERAV and AQERAV on inflexion ratio in Sodium nitrite induced amnesic model in mice (mean $\pm S E M)$.

\begin{tabular}{ccc}
\hline Treatment & Dose/kg & $\begin{array}{c}\text { Inflexion } \\
\text { Ratio(mean } \pm \text { SEM) }\end{array}$ \\
\hline Normal control(vehicle) & $10 \mathrm{ml} \mathrm{p.o.}$ & $0.410 \pm 0.016$ \\
Sodium nitrite alone & $25 \mathrm{mg} \mathrm{i.p}$ & $0.159 \pm 0.011$ \\
Piracetam + Sodium nitrite & $200 \mathrm{mg}$ p.o. $+25 \mathrm{mg}$ i.p & $0.695 \pm 0.033^{\star *}$ \\
AERAV + Sodium nitrite & $100 \mathrm{mg}$ p.o. $+25 \mathrm{mg}$ i.p. & $0.317 \pm 0.009^{\star}$ \\
AERAV + Sodium nitrite & $200 \mathrm{mg}$ p.o. $+25 \mathrm{mg}$ i.p. & $0.534 \pm 0.021^{\star *}$ \\
AERAV + Sodium nitrite & $400 \mathrm{mg}$ p.o. $+25 \mathrm{mg}$ i.p. & $0.605 \pm 0.031^{\star *}$ \\
AQERAV + Sodium nitrite & $100 \mathrm{mg}$ p.o. $+25 \mathrm{mg}$ i.p. & $0.314 \pm 0.011^{\star}$ \\
AQERAV + Sodium nitrite & $200 \mathrm{mg}$ p.o. $+25 \mathrm{mg}$ i.p. & $0.509 \pm 0.024^{\star}$ \\
AQERAV + Sodium nitrite & $400 \mathrm{mg}$ p.o. $+25 \mathrm{mg}$ i.p. & $0.569 \pm 0.029^{\star *}$ \\
\hline
\end{tabular}

$n=6$, Significant at $P<0.05^{\star}, 0.01^{* *}$ and $0.001^{* * *}$, ns $=$ not significant AERAVAlcoholic extract of roots of A. vasica AQERAV- Aqueous extract of roots of A. vasica

found to have no effect on locomotor activity. The results indicate that EERAV and AQERAV (100, 200 and $400 \mathrm{mg} / \mathrm{kg}$ ) with all doses and piracetam $(200 \mathrm{mg} / \mathrm{kg})$ treatment resulted in less trials and time to reach the criterion of conditioned avoidance learning. When tested after $24 \mathrm{hr}$, EERAV and AQERAV and piracetam $(200 \mathrm{mg} / \mathrm{kg})$ treated rats required significantly less trials, less shocked trials and less time to re-learn the task as compared with vehicle treated rats. All three doses of EERAV and AQERAV and piracetam have shown a significant nootropic activity. The EERAV and AQERAV (100, 200 and $400 \mathrm{mg} / \mathrm{kg})$ and piracetam $(200 \mathrm{mg} /$ $\mathrm{kg}$ ) when given along with PHT in the second week of the 2-week regimen significantly reversed PHT-induced impairment both on acquisition and retention. A protection was observed with all the parameters tested for Step-Down Latency (SDL), Time Spent in Shock zone (TSZ) and Step-Down Error (SDE). This indicates that all doses of EERAV and AQERAV except $100 \mathrm{mg} / \mathrm{kg}$ and piracetam have shown with significance in consolidation and retention of memory tested after $2 \mathrm{hr}$ and $24 \mathrm{hr}$ of initial latency of Step-Down Error (SDE). In EPM acquisition (learning) can be considered as transfer latency on 1st day trials and the retention/ consolidation (memory) is examined $24 \mathrm{hr}$ later. ${ }^{18}$ The animals shown a significant decrease in transfer latency as compared with the normal control group, which is an indication of the enhanced cognitive effect of all doses of EERAV and AQERAV except $100 \mathrm{mg} / \mathrm{kg}$ and piracetam in mice. The impairment of learning and memory induced by scopolamine $(1.0 \mathrm{mg} / \mathrm{kg})$ as an anti-cholinergic agent was reflected by prolonged TL from the open arm to the closed arm i.e., decreased IR was observed with EPM. ${ }^{19}$ The all doses of EERAV and AQERAV except $100 \mathrm{mg} / \mathrm{kg}$ and piracetam have reversed the amnesia induced by scopolamine, i.e. decreased TL from the open arm to the closed arm i.e., increased IR, indicates that extracts acting on Ach receptors because they have shown nootropic activity in presence of scopolamine which is a muscuranic receptor antagonist. Diazepam, a GABA mimetic agent induces memory impairment and the subsequent inhibition of GABA-B receptors has been found to facilitate learning and memory. ${ }^{20}$ Diazepam $(1 \mathrm{mg} / \mathrm{kg})$ has prolonged TL from the open arm to the closed arm i.e., decreased IR. The all doses of EERAV and AQERAV except $100 \mathrm{mg} / \mathrm{kg}$ and piracetam have decreased TL from the open arm to the closed arm i.e., increased IR thus confirms their nootropic activity. The protective effect offered by EERAV and AQERAV except $100 \mathrm{mg} / \mathrm{kg}$ and Piracetam against diazepam- induced amnesic model may be due to indirect release of Ach in the brain. Sodium nitrite impaired memory was through the cholinergic innervations i.e. it causes hypoxia leading to decreased oxygen content 
in the brain as suggested by Koziar et al. Sodium nitrite $25 \mathrm{mg} / \mathrm{kg}$ s.c. prolonged TL from the open arm to the closed arm i.e., decreased IR. The 3 doses of EERAV and AQERAV and piracetam shown significant decrease in transfer latency and increased the IR on Elevated plus maze apparatus. The protective effect exhibited by EERAV and AQERAV and piracetam against sodium-nitrite-induced amnesic model may be due to enhanced brain metabolism by increased oxygen content in brain. In this study we also accomplished the increased cessation of respiration time by all doses of EERAV and AQERAV and piracetam against sodium nitrite induced toxication. The sodium nitrite produces haemic hypoxia i.e., which reduces the oxygen-carrying capability of the blood by converting hemoglobin into methaemoglobin.

\section{CONCLUSION}

According to the Unani texts the plant A. vasica was reported for its therapeutic use in the treatment of loss of memory to improve this condition. EERAV and AQERAV have shown a significant nootropic activity in the active and passive avoidance models (Shuttle Box and Shock Box) wherein SDL, SDE and TSZ were recorded. The EERAV and AQERAV also has increased the IR in scopolamine, diazepam and sodium nitrite induced amnesia models which indicate the high retention of memory and the effect was found to be significant. Vasicinol was reported to possess anti-cholinesterase activity and the same constituents were present in the EERAV and AQERAV. Hence these phytoconstituents can be accounted for the observed nootropic activity.

\section{ACKNOWLEDGEMENT}

The authors are thankful to the management of Vaageswari College of Pharmacy for providing the necessary facilities to carry out the research work.

\section{CONFLICT OF INTEREST}

The authors declare no conflict of interest.

\section{ABBREVIATIONS}

AD: Alzheimer's Disease; OECD: Organization for Economic and Cooperation Development; CPCSEA: Committee for the Purpose of Conducting and Supervision of Experiments on Animals; AQERAV: Aqueous extracts of Roots of Adathoda vasica; EERAV: Ethanolic extracts of
Roots of Adathoda vasica; P.O: Per Oral; SDL: Step Down Latency; SDE: Step Down Error; TSZ: Time spend in Shock Zone.

\section{REFERENCES}

1. Reddy DS. Assessment of nootropic and amnestic activity of centrally acting agents. Indian J Pharmacol. 1997;29(4):208-21.

2. Bhattacharya SK. Text Book of Pharmacology $2^{\text {nd }}$ Edition, New Delhi. Elsevier. 2005;496-9.

3. Trivedi JK. Cognitive Deficits in psychiatric disorders: Current status. Indian J Psychiatr. 2006;48(1):10-20

4. Annapurna A, Ramakrishna V, Murali KK, Krishnakumar V, Prasad KB. Studies on nootropic activity of ramipril and losartan on scopolamine-induced amnesia in rats. Indian J Pharm Sci. 2004;66(1):31-5.

5. Ellen YS, Kathryn MU. Donepezil: Anti cholinesterase inhibitor for Alzheimer's disease. Am J Health Syst Pharm. 1997;54(24):2805-10.

6. Natural remedies for healthy brain and memory support (2000-2007, FDA). 2008. http://www.google.co.in/

7. Atul KG, Ashoke KG. Medicinal uses and Pharmacological activity of Adhatoda vasica. Int J of Herb Med. 2014;2(1):88-91.

8. Kirtikar KR, Basu BD. Indian medicinal plants, $2^{\text {nd }}$ ed, Vivek vihar Delhi. 1991;1899-901.

9. Parasuraman S. Toxicological screening. J Pharmacol Pharmacother $2011 ; 2(2): 74-9$.

10. ThakurVD, Mengi SA. Neuropharmacological profile of Eclipta alba (Linn) hassk. J Ethnopharmacol. 2005;102(1):23-31.

11. Hanumanthachar J, Milind P. Evaluation of nootropic potentials of Ocimum sanctum, Linn. in mice. Ind J Exp Biol. 2006;44(2):133-6.

12. Jaiswal AK, Bhattacharya SK. Effects of shilajit on memory, anxiety and brain monoamines in rats. Indian J Pharmacol. 1992;24(1):12-7.

13. Faroog SM, Alla TR, Venkat RN, Prasad K, Satyanarayana S, Nandakumar K, et al. A study on CNS effects of milk extracts of nuts of Semecarpus anacardium. Linn, (Anacardiaceae). Pharmacologyonline. 2007;1:49-63.

14. Ramanathan M, Ashok KSN, Suresh B. Evaluation of cognitive function of fluoxetine, sertraline and tianeptine in isolation and chronic unpredictable mild stress induced depressive wistar rats. Ind J Exp Biol. 2003;41(11):1269-72.

15. Venkat RN, Basavaraj P, Nimbal SK, Shantakumar SM, Satyanarayana S. Nootropic activity of tuber extract of Pueraria tuberose (roxb). Ind J Exp Bio. 2008;46(8):591-8.

16. Vikas K, Singh PN, Muruganandham AV, Bhattacharya SK. Effect of Indian Hypericum perforatum Linn on animal models of cognitive dysfunction. J Ethnopharmacol. 2000;72(1-2):119-28

17. Rodrigues $V$, Rao MS, Karnath S, Rao GM. Effect of Ocimum sanctum plant extract on learning behavior of stressed rats. Ind J Pharmacol. 1999;31:69

18. Achliya G, Barabde U, Wadodkar S, Dorle A. Studies on the effects of Bramhi ghirta, an polyherbal formulation on learning and memory paradigms in experimental animals. Ind J Pharmacol. 2004;36:159-62.

19. Iyer MR, Pal SC, Kasture VS, Kasture SB. Effect of Lawsonia inermis on memory and behaviour mediated via monoamine neurotransmitters. Ind J Pharmacol. 1998:30(3):181-5. Olpe HE, Orner W, Saito H, Matsuki N. Stimulation parameters determine role of GABA receptors in long-term potentiation. Experientia. 1993;49(6-7):542-6

Cite this article: Venu K, Mondal P, Rajesh BRC, Goje A, Sandeep G, Thimmaraju MK, Chanbasha S, Padmaja B. Evaluation of Nootropic activity of Ethanolic and Aqueous Root Extracts of Adhatoda vasica nees in Rodents. Int. J. Pharm. Investigation. 2018;9(4):180-6. 